\title{
Cystic Artery Haemostatic Control During Laparoscopic Cholecystectomy- Clips Or Bipolar Cautery - A Comparative Study
}

\author{
Authors \\ Ballapalli Hariprasad ${ }^{1}$, Mahidhar Reddy Venkatapuram ${ }^{2}$, Sreeram Satish ${ }^{3}$ \\ ${ }^{1}$ MS, FMAS, FIAGES, Assistant Professor of General Surgery, Narayana Medical College \& Hospital, \\ Nellore \\ ${ }^{2}$ MS, DIP.LAP SURGERY, Associate Professor of General Surgery, Narayana Medical College \& Hospital, \\ Nellore \\ MS, FIAGES, Professor \& HOD of General Surgery, Narayana Medical College \& Hospital, Nellore \\ Email: mdevishetty@gmail.com, Contactno-9703848030
}

Corresponding Author

Dr Ballapalli Hariprasad

Assistant Professor of General Surgery, Narayana Medical College \& Hospital, Chinthareddy Palem

Nellore, Andhra Pradesh.

\begin{abstract}
Aim of the study- we conducted this study to know which method is best,clip application or bipolar cautery, to secure haemostasis of cystic artery during laparoscopic cholecystectomy,

Methodology- a prospective comparative study was done on two groups of patients undergoing laparoscopic cholecystectomy ${ }^{l}$ where in cystic artery was clipped in group A and it was cauterized with bipolar device in group B. 50 patients were assigned to each group.

Results- in both the groups no one had postoperative bleeding. intraoperatively, in group A one patient needed reapplication of clip ${ }^{2}$ to cystic artery due to its slippage whereas in group B two patients had bleed from cystic artery after cauterization with bipolar device, which was subsequently controlled by clip application.

Conclusion-both clip application and bipolar cauterization are equally efficacious in gaining haemostasis of cystic artery during laparoscopic cholecystectomy.

Keywords- laparoscopic cholecystectomy, cystic artery, clips, bipolar cautery
\end{abstract}

\section{Introduction}

Today laparoscopic cholecystectomy is the gold standard procedure of choice for gall stone disease. it is one of the commonly performed laparoscopic procedure in general surgery departments. during standard laparoscopic cholecystectomy, after fundal retraction, calots triangle is dissected during which cystic artery is identified and secured. in majority of cases cystic artery arises from right hepatic artery ${ }^{4}$, in few cases it may arise from common hepatic, coeliac trunk, right gastric, superior mesenteric etc arteries. Proper haemostasis of cystic artery is must because it may result in torrential 
haemorrhage if not ligated properly and is the common cause of post operative bleeding after laparoscopic cholecystectomy. several methods are available for cystic artery control like clip application, bipolar diathery, monopolar diathermy, vessel sealing with ultrasonics, harmonics ${ }^{5}$ etc. among these monopolar diathermy is generally avoided because of lateral dissipation of heat and injury to adjacent structures. vessel sealers and harmonics are too costly to be affordable by all hospitals. Clip application and bipolar diathermy are cost effective and efficient methods. we conducted this study to see which one is better in the task.

\section{Methodology}

We designed a prospective comparative study by dividing patients undergoing laparoscopic cholecystectomy into two groups. Both the groups were assigned 50 patients each. In Group A cystic artery control was gained by clipping it with titanium clips. We have a practise of putting two clips normally. in group B cystic artery was cauterized with bipolar diathermy. in both the groups laparoscopic cholecystectomy was performed by surgeons who have atleast 5 years of experience in minimally invasive surgery ${ }^{6}$ and all surgeons followed standard procedure accepted and customized to our centre. abdominal drains were kept in morrisons pouch in all cases. postoperatively patients were observed for 2 days for any signs of bleeding from cystic artery. drains were checked regularly. ultrasound abdomen was done on both the days. vitals were checked and tabulated. more than $100 \mathrm{ml}$ of fresh blood in the drain bag or abdominal cavity was considered as significant bleed. patients were discharged on $3^{\text {rd }}$ day. all patients were informed and consent taken. Study protocol was approved by hospital ethics committee. this study was conducted at narayana medical college and hospital in general surgery department during the period may 2013 to july 2015.all patients with symptomatic gall stone disease were included in this study. Patients were selected on consecutive OP admissions and they were segregated into two groups by simple randomization. patients with cholecystitis ${ }^{7}$, choledocholithiasis, empyema gallbladder, pancreatitis, obstructive jaundice, chronic renal failure, portal hypertension and suspected malignancies were excluded from the study.

\section{Statistical Analysis}

SPSS latest version 2015 was used to analyze numerical data and expressed as mean+/-standard deviation (SD).observations were done in both the groups to look for any post operative bleeding. drain bag collection, vital data and ultrasound scan findings were taken into consideration. data of both the groups analysed. $\mathrm{P}$ value less than 0.05 was considered statistically significant.

\section{Results}

The median age of patients was $45.76 \& 49.02 \mathrm{yrs}$ (female \& male) in group A and $47.15 \& 49.65$ yrs (female \& male)in group B respectively. in group A female to male ratio was $3.5: 1$ and in group B it was $4.5: 1$. in group A cystic artery was single in $88 \%$ cases and was branched in $12 \%$ cases. in group B it was $94 \%$ \& $6 \%$ respectively. cystic artery was arising from right hepatic artery in $96 \%$ \& $92 \%$ cases in group A and group B respectively. postoperatively all the patients were observed for bleeding from surgery site by estimating the amount of fresh blood collectimg in the abdominal drain or abdominal cavity. more than $100 \mathrm{ml}$ of collection was considered significant bleed. none of the patients had post op bleeding in both the groups. Intraoperatively in group A, one patient had rebleed from cystic artery due to slippage of clips which was identified and stopped by reapplication of clips. Intraoperatively in group B, two patients had rebleed from cystic artery which was identified and stopped by clip application. all the data tabulated below. 
GROUP A

(clip application)

\begin{tabular}{|c|c|c|c|c|}
\hline & $\begin{array}{l}\text { Total } \\
\text { number of } \\
\text { cases }\end{array}$ & Percentage & $\begin{array}{l}\text { Total } \\
\text { number of } \\
\text { cases }\end{array}$ & Percentage \\
\hline $\begin{array}{l}\text { (1)sex } \\
\text { Prediliction }\end{array}$ & 50 & & 50 & \\
\hline Females & 39 & $78 \%$ & 41 & $82 \%$ \\
\hline Males & 11 & $22 \%$ & 9 & $18 \%$ \\
\hline $\begin{array}{l}\text { (2)median } \\
\text { Age }\end{array}$ & & & & \\
\hline Females & 45.76yrs & $\begin{array}{l}\text { NA (not } \\
\text { applicable) }\end{array}$ & $47.15 y r s$ & NA \\
\hline Males & $49.02 \mathrm{yrs}$ & NA & $49.65 y r s$ & NA \\
\hline $\begin{array}{l}\text { (3)cystic } \\
\text { Artery }\end{array}$ & & & & \\
\hline Single & 44 & $88 \%$ & 47 & $94 \%$ \\
\hline Branched & 6 & $12 \%$ & 3 & $6 \%$ \\
\hline $\begin{array}{l}\text { (4)cystic } \\
\text { artery } \\
\text { origin } \\
\end{array}$ & & & & \\
\hline Hepatic artery & 48 & $96 \%$ & 46 & $92 \%$ \\
\hline Other arteries & 2 & $4 \%$ & 4 & $8 \%$ \\
\hline $\begin{array}{l}\text { (5)during surgery } \\
\text { cystic duct rebleed }\end{array}$ & 1 & $2 \%$ & 2 & $4 \%$ \\
\hline (6)post operative bleed & 0 cases & $0 \%$ & 0 cases & $0 \%$ \\
\hline
\end{tabular}

\section{Discussion}

Cholilithiasis is increasing in incidence and is being managed by laparoscopic cholecystectomy. age and sex prediliction in our study was similar to that observed in the society. median age was $46 \mathrm{yrs}^{8}$ in females and 49 in males. it was females who were commonly affected ${ }^{9}$.during cholecystectomy one of the important step is to identify cystic artery in the calots triangle and gain control of it for a smooth surgery and perfect haemostasis. several methods are available for it like monopolar cautery, bipolar cautery, ultrasonicas, vessel sealing and clip application ${ }^{10}$ 11,12 .our study was designed to compare bipolar diathermy and clip application in their effectiveness. Our results showed no statistically significant difference between the two methods.

GROUP B

(bipolar diathermy) 
4. Huscher CG, Lirici MM, Di Paola M, Crafa F, Napolitano C, Mereu A, et al. Laparoscopic cholecystectomy by ultrasonic dissection without cystic duct and artery ligature. Surg Endosc. 2003;17(3):442-451.

5. Strasberg SM. Avoidance of biliary injury during laparoscopic cholecystectomy. J Hepatobiliary Pancreat Surg.2002;9:543547.

6. Khan S, Oonwala ZG. An audit of Laparoscopic Cholecystectomy, Pak J Surg. 2007;23:100-103.

7. Suzuki M, Akaishi S, Rikiyama T, Naitoh T, Rahman MM, Matsuno S. Laparoscopic cholecystectomy, Calot's triangle, and variations in cystic arterial supply. Surg Endosc. 2000;14:141-144.

8. Hugh TB, Kelly MD, Li B. Laparoscopic anatomy of the cystic artery. Am J Surg. 1992; 163:593-595.

9. Langenbuch C. A case of extirpation of the gallbladder for chronic cholecystitis. Cure. (Berlin) 1882; 19:725-727.

10. Soper NJ, Barteau JA, Claymann RV, Becich MJ; Safety and efficacy of laparoscopic cholecystectomy using monopolar electrocautery in the porcine model. Surg Laparosc Endosc., 1991; 1(1):17-22.

11. Champault A, Vons C, Dagher I, Amerlinck S, Franco D; Low-cost laparoscopic cholecystectomy. Br J Surg., 2002; 89(12):1602-1607.

12. Hannan MJ, Hogue MM; Laparoscopic cholecystectomy without handling the cystic artery: a new approach to minimize complications. J Laparoendosc Adv Surg Tech A., 2011; 21(10): 983-986. 